\title{
Editorial
}

\section{Palliation in AIDS—-where do we draw the line?}

"I conceive it the office of the physician not only to restore the health but to mitigate pain and dolours; not only when such mitigation may conduce to recovery but when it may serve to make a fair and easy passage."

Francis Bacon

Palliative medicine has recently entered adolescence by receiving Joint Committee on Higher Medical Training status as a subspeciality in the UK. However, it still remains a cinderella and those who see death, particularly among the young, as medical failure, have a negative view of the care of the dying as a laudable though fruitless attempt to ease what is always distressing, unwanted and unmanageable. Frequently, such clinicians consider that the potential for symptom control is limited and the refuge of the destitute. In many institutions still, there is a tendency when the avenues of active, curative strategies have been exhausted to consider palliation simply to be the withdrawal of treatment, because, "there is nothing more we can do", or at best "maybe some diamorphine would help."

The clinico-pathological case discussed in this issue shows clearly that palliation may be aggressive and have as real and quantifiable endpoints as "curative medicine". At the end of a person's life, though different, these objectives are equally if not more important than those familiar to the acute physician.

As with so many areas, AIDS has stimulated the need for evaluation of clinical practice at the interface between curative and palliative care. The syndrome has many facets that are in themselves treatable although the overall prognosis is fatal; hitherto, it has affected predominantly those in the third and fourth decades, and the pursuit of cure and clinical experience of an epidemic in evolution has understandably made many reticent to "give up" even in the most pessimistic circumstances. Furthermore, this disease has emerged amongst a generation who expect informed involvement in their clinical care at all stages.

AIDS therefore raises some interesting, important and interconnected issues in the management of the terminally ill. For example, what criteria should be applied in balancing a patient's right to autonomy in management strategy with the clinicians perception of their best interests? To what extent should one go clinically to facilitate the patient in his or her wishes? Having made the philosophical decision to palliate, should one then utilise to the full the technology and resource of modern clinical practice to meet these ends?

The verb to palliate comes from the latin, to cloak. It has been used figuratively to mean disguise or hide, and when applied to medicine was used first in the 16th century to describe the alleviation or mitigation of suffering. ${ }^{1}$ In the Hospice movement, palliation has traditionally been referred to the management of patients in whom death is almost certain and not too far off, where the control of symptoms is the prime clinical objective, and the emotional and spiritual preparation of both patients and "family" is given high priority. ${ }^{2}$

Dunstan $^{3}$ sees the objectives to be an inevitable "mortal end . . with the minimum of distress and the maximum capacity to enjoy or even repair such human relationships as s/he might choose". Thus the management of a patient at one time may be to maintain quantity and quality of life with aggressive management, and following resolution of issues, a time may come where medication administered for the control of distress. . . (may) putatively speed up the patient's death." Convention within British clinical practice, regardless of what is taught about holistic medicine, places the decision-making in management with the doctor. The criteria or fulcrum on which management is balanced rest primarily upon pathology, prognostic indicators, or objective side effects (that is, iatrogenic disease, such as marrow suppression), whereas palliative philosophy considers quality of life or a patient's plans and objectives as the more appropriate focus. So for example, in debating the benefit of a planned intervention, the possibility of an increased median survival or reduced long term morbidity may be overridden by the certainty of valuable time "wasted" in hospital or some immediate cosmetic or social consequence when short term benefit is the order of the day. The physician's role within palliation is therefore broadened to that of facilitator as well as diagnostician. Equally, the familiar role of decision maker may change to that of informant and advocate.

Thompson, another ethicist, appeals to the basic 
human right to privacy in his argument for the broadest remit of palliative care. ${ }^{4} \mathrm{He}$ maintains that this incorporates the patient's right to be involved in decision making, his or her right to decline medication and investigation on the one hand and the right to treatment in the context of terminal care on the other. Clearly, this may ultimately mean the right to a good death with dignity or grace which incorporates emotional, practical and spiritual support as well as the best clinical care. In fulfilling these requirements, therefore, palliation may be rather more than simply "settling for comfort", by active apprehension of the means and the environment in which integration can finally occur using the technology and expertise that will make this possible. Fundamental to this line of reasoning is a sharing of the responsibility for treading the narrow path by the patients, their loved ones and the professionals involved, within a framework of true multidisciplinary care. ${ }^{5}$

The practical applications of these principles are seen par excellence in the case discussed in this issue. Following a long and harrowing illness, the patient's clinical state was such that adequate hydration, nutrition and medication could only be achieved parenterally. As the patient and "family" began facing the reality of his prognosis and the size and nature of his emotional and spiritual agenda, going home to die was stated as an absolute requirement. The sense of safety, identity and control that comes with familiar objects and surroundings has been established for many years ${ }^{6}$ both for those dying in hospital ${ }^{7}$ and also for those dying at home ${ }^{89}$ Much of the counselling work done with the patient would only have been possible in the security of familiar and "safe surroundings". Hence the benefit of being at home was seen to override all but the most extreme cost. The resolve of the patient and carers was matched by available technology and clinical skill to make the stated goals reachable within a philosophical framework of palliation. In this respect an open discussion with the friends and partner of the patient about the limitations of care was an essential first step to making a move home, particularly in view of the strictures of total parenteral nutrition and the need for regular systemic drugs. Whilst the administration of parenteral nutrition at home may be considered by some as extreme, it is by no means a precedent in palliative medicine.$^{10}$ The first phase of palliation in this case was therefore aggressive, technical and had clear objectives.

At the appropriate time, dictated by the patient, further active intervention ceased and the dying process took its natural course without interruption, eased by specific symptom control. Here palliation was truly a cloaking of the pathological processes with the use of opiates and hyoscine to control respiratory symptoms and steroids to ablate the discomfort of nausea and the effect of systemic upset from septicaemia. In summary then, the fulcrum of the balance between cure and palliation were intentionally the objectives and agendas of the patient rather than the pathologies involved.

Whether an early diagnosis and treatment of CMV colitis would have made any lasting difference to quality or quantity of life, we shall never know. However, the failure to address this particular possibility at an early stage is certainly an important and valid observation.

Thompson ${ }^{4}$ sums up these challenges as follows:

"Good terminal care requires and pre-supposes the active and voluntary co-operation of the patient in the management of his own death. Open and frank recognition of a situation as terminal and the conscious decision to switch from therapeutic measures to palliative care raises in acute form the question of a patient's right to some say in where, how and when he dies, and his right, so far as he is able, to make of his death a meaningful personal act and significant event. The question is how far medical and nursing staff are prepared to facilitate these possibilities"

For those of us caring for people with AIDS, the dilemma as we face end stage disease with a patient may be acute. However, to see palliation in its true sense as a positive approach to such care will lead to better quality life right up to the point of death and a much greater sense of completion for professional and patient alike.

RJD GEORGE
University College and Middlesex School of Medicine,
Community Care Team,
National Temperance Hospital,
Hampstead Road,
London NW1 $2 L T, U K$

1 The Oxford English Dictionary Oxford. Oxford University Press, 1963.

2 Holford JM. Terminal Care, Care of the Dying. Proceedings of a national symposium held on 29 November 1972. London, HMSO, 1973 .

3 Dunstan GR. Clarifying the issues. In: Twycross RG, Ventafridda V, eds. The Continuing Care of Terminally Ill Cancer Patients. London, Pergamon Press, 1983.

4 Thompson I. Ethical Issues in Palliative Care. In: Doyle D, ed. Palliative Management of Far Advanced Disease. London, Croomhelme 1984.

5 Saunders C. Hospice and Palliative Care, an Interdisciplinary Approach. London, Edward Arnold, 1990.

6 Peabody H. The care of the patient. JAMA 1927;8:887-9.

7 Rossman I, Kissick WL. Home Care and the Cancer Patient. In: The Physician, the Total Care of the Cancer Patient. New York, The American Cancer Society, 1961.

8 Aitken Swan J. Nursing the late cancer patient at home. Practitioner 1959;183:64.

9 Illich I. Limits to Medicine. Hammonsworth, Penguin 1976.

10 Bozzetti F. Intravenous feeding. In: Twycross RG, Ventafridda V, eds. The Continuing Care of Terminally Ill Cancer Patients. London, Pergamon Press, 1983. 